Artículo de Investigación

Apuntes del CENES

ISSN 0120-3053

Volumen $34-\mathrm{N}^{\circ} .60$

julio - diciembre 2015

Págs. 181-214

\title{
Realidad fiscal de los municipios del departamento de Santander, en el marco del proceso de descentralización fiscal en Colombia, 2004-2012
}

Fiscal reality of the municipalities of the Santander Department in the framework of the process of the fiscal decentralization in Colombia, 2004-2012

Realidade fiscal dos municípios do Santander no contexto da descentralização fiscal na Colômbia, 2004-2012

Jorge Enrique Asela Molina *

Fecha de recepción: 12 de septiembre de 2014 Concepto de evaluación: 13 de enero de 2015

Fecha de aprobación: 13 de enerode 2015

Economista de la Universidad Industrial de Santander (UIS). Consultor en políticas de desarrollo territorial. Bucaramanga. Colombia. Correo postal: Avenida el Tejar 104-25, Urbanización Fátima casa 21-C. Bucaramanga, Santander Colombia. Correo electrónico: jorgeasela@hotmail.com 


\section{Resumen}

Este documento explora el proceso de descentralización en Colombia desde su marco normativo y su relación con las finanzas públicas de los municipios del departamento de Santander, por medio del análisis de la situación fiscal de los entes territoriales del departamento durante 2004-2012. Para este ejercicio se toman como referencia los indicadores de dependencia intergubernamentales y esfuerzo fiscal, planteados por el Departamento Nacional de Planeación (DNP). Se evidencian, en la mayoría de los casos, problemas en la generación de recursos propios y un alto grado de dependencia de las transferencias del Gobierno central.

Palabras claves: descentralización, Estado, entes territoriales, dependencia intergubernamental, esfuerzo fiscal, departamento de Santander.

Clasificación JEL: E62, H11, H72, K00, R58.

\section{Abstract}

This document explores the decentralization process in Colombia through its normative framework and its relation with the public finances of the municipalities of Santander Department, by means of the analysis of fiscal situation of local authorities of the Department during 2004-2012. For this exercise have been taking as reference the indicators of intergovernmental dependence and fiscal effort, proposed by the National Department of Planning (DNP, by its Spanish acronym), showing in most of the cases problems in the generation of own resources and one high degree of dependence from the transfers of the central government.

Keywords: decentralization, state, local authorities, intergovernmental dependence, fiscal effort, Santander Department. 


\section{Resumo}

Este artigo explora o processo de descentralização na Colômbia através do quadro regulamentar que converge e sua relação com as finanças públicas dos municípios de Santander, que através da análise da situação fiscal das autoridades locais do departamento durante o período entre os anos de 20042012 , o exercício realizado com base nos indicadores de dependência e de esforço fiscal intergovernamental levantada pelo Departamento Nacional de Planejamento (DNP), mostrando na maioria dos casos os problemas na geração de recursos próprios e alto grau de dependência das transferências do governo central.

Palavras chave: Descentralização, Estado, Entidades Territoriais, Dependência, esforço fiscal, Santander. 


\section{INTRODUCCIÓN}

En Colombia el modelo de desarrollo del Estado ha girado en torno a una estructura altamente centralizada, la cual empezó a presentar cambios en las dos últimas décadas del siglo $\mathrm{XX}$, como respuesta a las crisis presentadas en los sectores económico, político y social. Estos hechos, sumados a la tendencia internacional que fomentaba una alternativa a la centralización como modelo de manejo del Estado, permitieron que surgiera en Colombia el modelo de descentralización como la opción para cumplir el mencionado rol. El proceso de descentralización, que presentó avances importantes durante la década del 80 , se afianzaría en los años 90 con la proclamación de la Constitución Política de 1991, hecho que permitió a los entes subnacionales contar con cierta autonomía política, administrativa y fiscal (Asela, 2014).
A partir de la perspectiva teórica del proceso de descentralización, el presente documento muestra desde el punto de vista normativo, la evolución del proceso de descentralización en Colombia y su influencia en las finanzas públicas de los municipios del departamento de Santander, en el periodo comprendido entre los años 2004-2012. Su objetivo es describir la realidad fiscal de los municipios del departamento de Santander durante el periodo mencionado, mediante el comportamiento de los indicadores de dependencia intergubernamental y esfuerzo fiscal planteados por el Departamento Nacional de Planeación (DNP).

El análisis del documento se plantea para mostrar la forma en que el proceso de descentralización fiscal en Colombia 
ha repercutido en las finanzas públicas de los municipios del departamento de Santander, señalar el grado de influencia del Gobierno central sobre las finanzas municipales y evidenciar la capacidad de los entes territoriales para generar recursos propios.

La metodología implementada para el análisis de la realidad fiscal de los municipios del departamento de Santander se enfoca en el estudio de los indicadores de desempeño fiscal -dependencia intergubernamental y esfuerzo fiscal- planteados por el DNP durante el periodo comprendido entre el 2004 y el 2012. Se presentan tres categorías para cada indicador: dependencia intergubernamental: $\sin$ dependencia, moderada dependencia, totalmente dependiente; esfuerzo fiscal: sobresaliente, bueno, malo. A fin de indicar de manera descriptiva el comportamiento de los municipios.

En la primera parte del documento se presenta el modelo de descentralización como estructura de manejo del Estado, desde una perspectiva teórica. En la segunda parte se muestra el proceso de descentralización en Colombia, con fundamento en el marco normativo, principalmente en el campo fiscal. Finalmente se hace un análisis sobre la realidad fiscal de los municipios del departamento de Santander, durante el periodo comprendido entre los años 2004-2012, con base en la descripción de los indicadores de dependencia intergubernamental y esfuerzo fiscal.

\section{LA DESCENTRALIZACIÓN}

Una de las definiciones más usadas sobre la descentralización es la planteada por Rondinelli, McCullough y Johnson (1989), la cual la describe como una reforma de carácter político-administrativa, y la define como «la transferencia de responsabilidades de planificación, gerencia, recaudación y asignación de recursos desde el gobierno central y sus agencias a unidades territoriales $\gg{ }^{1}$ (Rondinelli et al., 1989, p. 58-59); cuyo principal fin es aumentar la eficiencia de la administración pública. A su vez, los autores referencian la existencia de cuatro tipos de descentralización: desconcentración, delegación, devolución y privatización. En primer lugar plantean la desconcentración como transferencia de responsabilidades de índole administrativo desde el nivel alto de Gobierno hacia las instancias inferiores. La delegación es entendida como la entrega de facultades en busca de una mayor autonomía administrativa, pero con responsabilidades financieras sobre políticas públicas, siempre condicionadas a la rendición de cuentas al Gobierno central. La devolución se propone como el traspaso de autoridad y financiamiento desde el nivel superior de Gobierno hacia los entes subnacionales, que genera la potestad de la cobranza de rentas por medio de tarifas impositivas.

Texto original en ingles "the transfer of responsibility for planning, management, and the raising and allocation of resources from the central government and its agencies to field units of government agencies". 
La privatización consiste en dejar en manos de la competencia entre agencias púbicas y privadas la provisión de bienes y servicios.

La evolución a lo largo del tiempo sobre la definición del término descentralización que desarrollaran Rondinelli et al., (1989), ha significado el replanteamiento sobre los tipos de descentralización propuestos por los mencionados autores, y ha hallado el consenso académico en la «devolución» como tipo de descentralización, y en la desconcentración y delegación como características del mismo proceso (Mardonez, 2008). Es por ello que en el marco de la estructura de organización de los Estados, la descentralización en tiempos más recientes es entendida como un proceso políticoadministrativo, que consiste en la transferencia de responsabilidades, recursos y funciones desde el órgano central del Estado hacia sus entes territoriales (Triesman, 2002).

El proceso de descentralización, como estructura para el manejo del Estado, de acuerdo con Finot (2002), cuenta con una serie de objetivos en los diferentes ámbitos de la administración pública, los cuales se centran en primera instancia en la esfera política, como base para posteriores pasos en los ámbitos administrativo y fiscal. Para Finot (2002), los principales objetivos del proceso de descentralización en esta etapa son: 1) suscitar una participación constructiva, 2) aumentar la eficiencia de la administración pública, y 3 ) mayor equidad territorial y social.
Para la obtención de estos objetivos hay factores fundamentales, como la ampliación de los centros de decisión, mayor agilidad y flexibilidad en la toma de decisiones por parte del Estado hacia las localidades y la apertura hacia un pluralismo político. Estas medidas presuponen, entre otras cosas, una mejor lectura de las preferencias de los individuos, dada la cercanía de los gobernantes locales y sus comunidades, así como una actuación más ágil frente a los problemas que se suscitan en las localidades, a fin de aumentar la eficiencia de la administración pública, principal objetivo de la descentralización (Baguenard, 1994).

Dentro del proceso de descentralización del Estado, este puede ser asumido desde diferentes perspectivas o como un conglomerado de estas. Cohen y Peterson (1996) las clasifican de acuerdo con sus características, como: descentralización espacial, descentralización hacia el mercado, descentralización política $\mathrm{y}$ descentralización administrativa.

- Descentralización espacial: es entendida como la transferencia de recursos e instrumentos a los entes territoriales, con el fin de promover actividades de índole económica e industrial, intentando impedir la concentración de dichas actividades en los principales centros urbanos.

- Descentralización hacia el mercado: es vista como la transferencia de responsabilidades en la prestación de bienes y servicios públicos desde el 
Estado hacia el sector privado.

- Descentralización política: radica en la libre elección de los gobernantes locales, en la mayoría de los casos vía voto popular, a su vez que estos gobernantes tengan la potestad de tomar decisiones relacionadas con el desarrollo de sus localidades.

- Descentralización administrativa: consiste en la transferencia de funciones, recursos y capacidades de decisión desde el gobierno central a los entes territoriales, con el fin de garantizar la provisión de determinados bienes y servicios públicos.

La descentralización administrativa se manifiesta en: (i) desconcentración, (ii) delegación y (iii) devolución. (i) La desconcentración es tomada como la redistribución del poder de decisión del Gobierno central, hacia los entes territoriales o entidades públicas. Es un proceso que se da dentro de una misma unidad organizacional, con una única unidad de mando y dirección, además se puede presentar en los diferentes niveles de Gobierno (central, departamental, municipal). (ii) La delegación, como su nombre lo indica, permite delegar facultades que reconozcan una mayor autonomía administrativa con responsabilidades financieras sobre políticas públicas, sin dejar de rendir cuentas al Gobierno central. Finalmente, (iii) la devolución consiste en la entrega de autonomía política a los dos anteriores procesos -desconcentración, delegación- permitiendo a los gobiernos locales tomar decisiones sobre las políticas de desarrollo dentro de sus localidades.

A la clasificación sobre las diferentes manifestaciones del modelo de descentralización cabe agregar una más, la descentralización fiscal. La descentralización fiscal cuenta con características de la descentralización administrativa que hacen que sean parecidas, ya que ambas tienen como base la transferencia de recursos; aunque una diferencia sustancial que hace que estas puedan desligarse es la autonomía en la formulación de nuevos impuestos por parte de los gobiernos locales. En palabras de Falleti (2005), «la descentralización fiscal se refiere al conjunto de políticas diseñadas para aumentar los ingresos o autonomía fiscal de los gobiernos subnacionales $»^{2}$ (Falleti, 2005, p.329). O como lo dice Schneider (2003), esta «se refiere a cómo los gobiernos centrales ceden parte del impacto fiscal a los gobiernos no centrales» $\rangle^{3}$ (Schneider, 2003, p.33).

De acuerdo con lo visto líneas arriba, la descentralización puede ser entendida como la transferencia desde el Gobierno central de competencias a los entes subnacionales, las cuales deben ir acompañadas de condiciones básicas a

\footnotetext{
$2 \quad$ Texto original en inglés "Fiscal decentralization refers to the set of policies designed to increase the revenues or fiscal autonomy of subnational governments".

3 Texto original en inglés "refers to how much central governments cede fiscal impact to non-central government entities".
} 
nivel político, administrativo y fiscal, permitiéndoles asumir parte de las funciones del ente central.

MARCO NORMATIVO DE LA DESCENTRALIZACIÓN EN COLOMBIA, PRIMEROS PASOS Y SUS ETAPAS (1983-1990), 1991 EN ADELANTE

\section{Primeros pasos de la descen- tralización en Colombia}

La descentralización es una forma de organización del Estado, en la cual la administración pública se organiza entre el Gobierno central y los gobiernos subnacionales, los cuales tienen facultades tributarias y de asignación del gasto. Este sistema permite que la toma de decisiones se acerque al ciudadano, es decir, que presupone un acercamiento a las instancias del poder por parte de la ciudadanía; lo que se traduce en una mejor comprensión de la revelación de sus preferencias en materia de bienes y servicios públicos. Se considera que un sistema descentralizado conlleva la eficacia, eficiencia y compromiso en la administración de los recursos y las entidades del Estado (Falleti, 2005).

En América Latina el proceso de descentralización inicio tardíamente, comparado con otras regiones -finales de la década del ochenta y principios del noventa del siglo $\mathrm{XX}_{-}$, producto del legado centralista heredado de la época de la colonia. A principios de la década de los ochenta el modelo centralista fue perdiendo terreno en América Latina, como consecuencia de la caída de las dictaduras militares que gobernaron buena parte de los países de la región, tras estas caídas y la vuelta a la democracia, se empezaron a dar reformas que transformaron el panorama de los entes subnacionales, entre las cuales están la elección por parte del pueblo de gobernantes locales y la cesión de funciones administrativas desde el Gobierno central.

Colombia es uno de los países que desde principios de los ochenta ha venido consolidando el proceso de descentralización hacia los gobiernos territoriales. Básicamente motivaron este proceso las fallas en cobertura y calidad de los servicios públicos (salud y educación), para lo cual la Constitución Política estableció una mayor autonomía fiscal y política a los gobiernos subnacionales, en donde juegan papel fundamental las transferencias intergubernamentales y el fortalecimiento de la democracia local.

Para Porras (2005), la descentralización, entendida como proceso dinámico, se ha consolidado a lo largo de la historia del país con base en principios como: la especialización, mediante la definición de competencias entre niveles de gobierno; la sostenibilidad en la asignación de fuentes de ingreso, como garantía al correcto manejo de las nuevas responsabilidades; la responsabilidad en el sentido político del establecimiento de un compromiso entre el gobernante 
y sus electores; y la integral, dada la convergencia de instrumentos en áreas de índole fiscal, política e institucional.

De acuerdo con Lleras y Posada (1991), en materia fiscal la descentralización en Colombia presenta sus orígenes en el Gobierno de Lleras Restrepo (1966-1970). En primer lugar con la Ley 33 de 1968, en la cual se estableció el fortalecimiento de los fiscos seccionales, permitiendo a los entes territoriales la participación de un porcentaje del impuesto sobre las ventas. En segundo lugar con la Ley 46 de 1971, la cual se presentó tras la llamada Misión Musgrave ${ }^{4}$, la cual entre sus conclusiones sugirió la necesidad de aumentar el número de bienes y servicios públicos que debe provee el Estado, y se recomendó que dicha prestación se realizase directamente desde los departamentos, es por ello que bajo esta ley se crea el situado fiscal ${ }^{5}$.

Según Iregui, Ramos y Saavedra (2001), si bien las transferencias bajo el mecanismo de situado fiscal representaron un avance en materia de descentralización, el esquema centralista se mantuvo, debido a que el poder político aún era exclusividad del Gobierno central; lo que permitió que los recursos de educación y salud, que eran manejados por los departamentos, se concentraran ahora en instituciones descentralizadas de orden nacional como los fondos educativos regionales (FER) y los servicios seccionales de salud (SSS).

Con el Gobierno de Turbay, que comprendió el periodo de 1978 a 1982, se vuelven a reconocer como problemas las prácticas centralistas y la falta de autonomía regional. En el Plan de Integración Nacional propuesto para este Gobierno, se entendía la descentralización como objetivo fundamental de la política económica. Para ello era necesario establecer la función de los municipios $\mathrm{y}$ departamentos en materia fiscal y, de esta manera, propiciar el mejor aprovechamiento de la base tributaria de estos, lo que generaría una disminución de la dependencia de las transferencias nacionales, lo que se concretaría en años posteriores.

\section{Primeraetapadeladescentralización en Colombia (1983-1900)}

La primera etapa de la descentralización en Colombia se establece en el periodo que va desde el año 1983 hasta 1990, se inicia con la Ley 14 de 1983, la cual buscaba la descentralización fiscal a través de reformas en la estructura de impuestos municipales y departamentales, lo que resultaría en el fortalecimiento de las finanzas públicas subnacionales. Entre otras reformas, se modificó la base y la tasa del impuesto

\footnotetext{
$4 \quad$ Misión que se creó con el fin de estudiar la situación de las finanzas públicas del país.

5 Transferencia obligatoria de un porcentaje del ingreso del Gobierno central hacia los departamentos y el Distrito Capital, con destinación específica en salud pública y educación primaria.
} 
de industria y comercio, e impuestos de consumo al licor y cigarrillos, además de la cesión a los departamentos del impuesto de timbre de vehículos. Como consecuencia de esta ley se produjo la actualización de la base del impuesto predial, se adoptó el impuesto de circulación y tránsito; reformas que permitieron que esta ley fuese conocida como el estatuto de Tributación Nacional.

Esta distribución de la estructura fiscal del Estado -mencionada líneas arriba en la Ley 14 de 1983- entre los diferentes niveles de Gobierno, para Lleras (1991) obedece a dos criterios básicos: «economías de escala en la administración de impuestos y la capacidad efectiva de controlar el recaudo» (Lleras \& Posada, 1991, p. 64). A partir de esto, la nación debería recaudar sobre actividades de factores móviles de producción de las regiones.

Se redefine en años posteriores el papel de los departamentos, mediante las leyes 22 de 1985 y 3 de 1986, donde se establecen como instancias intermedias encargadas de participar y supervisar la creación y ejecución del plan de desarrollo.

De acuerdo con Porras (2005), en 1985 con la Ley 75 se crean los consejos regionales de planificación económica (CORPES), convirtiéndose en las principales entidades de planeación regional. Con ello se pretendía el fortalecimiento de la planeación territorial, la participación en los planes de desarrollo y la programación del presupuesto de las entidades de orden regional. Estos objetivos y las normas fueron confusos, lo que se tradujo en una duplicidad de funciones y de gasto.

Para finales de la década de los ochenta se presentan grandes avances en los campos político, administrativo y fiscal. En el ámbito político, con el Acto Legislativo 1 de 1986, mediante el cual se establece la elección vía voto popular de alcaldes -ley que entraría en vigencia dos años después-, se busca fortalecer los gobiernos locales y hacerlos más sensibles a las preferencias de sus habitantes. En lo concerniente al campo administrativo, la Ley 12 de 1986 modificó el porcentaje cedido a los departamentos y municipios por concepto del impuesto al valor agregado (IVA), además de la forma de asignación y causal de disponibilidad para dichos recursos, para ello se asignaron nuevas competencias. Adicionalmente, mediante el Decreto 77 de 1987 se autorizó al Gobierno central fusionar, reformar o liquidar entidades que prestaran los servicios contemplados en la cesión de recursos, se estableció la estructura funcional y de responsabilidad sobre la prestación de servicios públicos a nivel local y se creó el sistema de cofinanciación como instrumento de inversión pública.

Posteriormente, en 1989, también en el ámbito administrativo, con la Ley 29 se entrega la facultad a los alcaldes del 


\section{el numeral 2 esta repetido}

Apuntes Cenes Vol. 34, Nº. 60, ISSN 0120-3053

julio - diciembre 2015, Págs. 181-214

nombramiento de docentes y personal adicional en las escuelas públicas, sin afectar las finanzas de las localidades, ya que el pago de esos nombramientos se haría desde el Gobierno central. Con la Ley 57 de 1989 se crea la Financiera de Desarrollo Territorial (FINDETER) como órgano de acompañamiento y financiamiento de proyectos de infraestructura urbana a nivel local y regional.

Por su parte, en el plano fiscal se estableció el sistema de cofinanciación como instrumento de inversión pública (Decreto 77/87), con la Ley 44 de 1990 se estructura el impuesto predial unitario, autorizando a los concejos el establecimiento de tarifas dentro de un rango $^{6}$, lo que generaría mayores recursos para los gobiernos locales.

Las reformas formuladas en la primera etapa del proceso de descentralización en Colombia, tuvieron dos objetivos. Según Iregui, Ramos y Saavedra (2001), el primero era el deseo del Gobierno central de descongestionar responsabilidades de gasto territorial de su presupuesto, ya que se afrontaba una crisis y deterioro de las finanzas nacionales; el segundo se refería al propósito de ampliar la cobertura, mejorar la eficiencia y la calidad del gasto público, para lo cual los departamentos y municipios entrarían a jugar un papel importante. En resumen, esta etapa se caracterizó por sentar las bases que fortalecerían el proceso de descentralización en Colombia, presentando grandes avances en los planos político, fiscal y administrativo.

\section{Segunda etapa de la descentra- lización en Colombia, 1991 en adelante}

La segunda etapa de la descentralización en Colombia inicia con la promulgación de la Constitución de 1991, la cual presenta cambios importantes en el proceso de descentralización, referentes a orientación territorial y política, distribución de competencias y funciones entre los distintos niveles de Gobierno, distribución de recursos entre los diferentes niveles de Gobierno, procesos de planeación, de presupuesto público, y sistemas de control fiscal.

La nueva Constitución (1991), en su artículo 1, organiza el país en una «república unitaria, descentralizada con autonomía de sus entidades territoriales...», a su vez plantea en su artículo 303, haciendo referencia a la descentralización política, la elección de gobernadores por medio del voto popular.

Haciendo alusión a la división políticaadministrativa del país se define al municipio en el artículo 311 de la Constitución, como:

Entidad fundamental de la división político-administrativa del Estado

6 De acuerdo con Garay (1994, p. 50) es de "1 a 16 por mil del avalúo catastral autorizándose una tarifa superior, con un límite de 33 por mil, para los pedios urbanizables no urbanizados y los urbanizados no edificados". 
le corresponde prestar los servicios públicos que determine la ley, construir las obras que demande el progreso local, ordenar el desarrollo de su territorio, promover la participación comunitaria, el mejoramiento social y cultural de sus habitantes y cumplir las demás funciones que le asignen la Constitución y las leyes.

En lo correspondiente a la organización territorial se abrieron posibilidades de crear nuevos entes territoriales como:

- Regiones

- Provincias

- Distritos especiales

- Áreas metropolitanas

- Territorios indígenas

Todos estos nuevos entes territoriales, según el artículo 287, gozan de total autonomía dentro de los límites de la Constitución y la ley, lo que garantiza que sean gobernados por autoridades propias. Se establece, además, la participación de las rentas del Gobierno central y la posibilidad de generar recursos propios que les permitan cumplir con sus funciones en el marco de sus competencias.

En el plano fiscal se establece en el marco de una mayor autonomía fiscal la cobranza de impuestos por parte de los entes territoriales para el cumplimiento de las funciones impuestas en el artículo 287. Impide, a través del artículo 362, que la nación se apropie de los recursos que vía impuestos capten los entes territoriales, salvo en caso de guerra exterior, y dispone la prohibición de sobretasa o excepciones de ley en los impuestos territoriales (art. 294).

Las transferencias intergubernamentales, como complemento del presupuesto de los entes territoriales, juegan un papel importante en el desarrollo de la finalidad de las localidades. Para lo cual, la Constitución Política de Colombia establece en los artículos 356 las transferencias a los departamentos, y en el artículo 357, las transferencias a los municipios, a su vez, dispone en los artículos 360 y 361 los temas correspondientes a las regalías.

Lo dispuesto en los anteriores artículos $-356,357,360$, y 361- se centra en la utilización de los recursos provenientes de las transferencias. El situado fiscal solo puede ser utilizado en programas referentes al sector de salud y educación pública, las transferencias a los municipios solo pueden invertirse en el campo social, no se podrá inferir responsabilidades nuevas a los entes subnacionales sin un previo aumento en los recursos transferidos. Además se plantea que los recursos provenientes de la explotación de recursos no renovables deberán ser entregados vía regalías a los entes territoriales en cuya jurisdicción se realiza la explotación o se transporten vía marítima productos o derivados de dicha explotación. 
Posteriormente a la expedición de la Constitución de 1991, se promulgan las leyes que la reglamentan. La Ley 60 de 1993 regula lo establecido en los artículos 151, 288, 356 y 357 de la Carta Magna, sobre distribución, asignación de recursos y competencias. En materia de descentralización administrativa esta ley dicta las competencias de los entes subnacionales, principalmente en sectores como educación, salud, vivienda y saneamiento básico (ver Tabla 1). En el ámbito fiscal, entre otras disposiciones, otorga al Departamento Nacional de Planeación (DNP) el control de la asignación de las transferencias a los entes territoriales. Estas transferencias se entregan bajo una fórmula de distribución, dando principal importancia a los municipios con menos de 50.000 habitantes y a los territorios indígenas. Para las fórmulas se tienen en cuenta variables como población, necesidades básicas insatisfechas, esfuerzo fiscal local y eficiencia administrativa. 
Tabla 1. Competencias y funciones bajo la Ley 60 de 1993, sectores sociales

\begin{tabular}{|c|c|c|c|}
\hline Sector & Nivel central & Nivel departamental & Nivel municipal \\
\hline $\begin{array}{c}\text { Rol } \\
\text { general }\end{array}$ & $\begin{array}{l}\text { Formular políticas. } \\
\text { Distribuye y transfiere } \\
\text { recursos del situado } \\
\text { fiscal. Administra los } \\
\text { fondos de cofinanciación. } \\
\text { Aconseja a las } \\
\text { entidades territoriales. } \\
\text { Evalúa la prestación } \\
\text { de servicios. }\end{array}$ & $\begin{array}{l}\text { Planea, administra y } \\
\text { Distribuya recursos } \\
\text { entre los municipios. } \\
\text { Provee ayuda financiera } \\
\text { y aconseja a los } \\
\text { municipios. }\end{array}$ & $\begin{array}{l}\text { Provee los servicios básicos: } \\
\text { salud, y educación en el primer } \\
\text { nivel, agua potable y sanidad, } \\
\text { vivienda y otros que indica la } \\
\text { ley. }\end{array}$ \\
\hline Educación & $\begin{array}{l}\text { Deja de ser } \\
\text { responsable de asuntos } \\
\text { administrativos } \\
\text { relacionados con } \\
\text { educadores nacionales. } \\
\text { Determina salarios } \\
\text { de acuerdo con la ley. } \\
\text { Conduce el seguimiento } \\
\text { y los servicios de } \\
\text { evaluación. }\end{array}$ & \begin{tabular}{|l|} 
Planea, administra y coor- \\
dina servicios educativos. \\
Administra y entrena \\
a los profesores, de \\
acuerdo con la ley. \\
Transfiere gradualmente \\
funciones a los municipios. \\
Administra fondos de cofi- \\
nanciación para los munici- \\
pios con recursos locales.
\end{tabular} & $\begin{array}{l}\text { Administra la educación } \\
\text { preescolar, primaria y secundaria } \\
\text { de acuerdo con los términos } \\
\text { de cambio departamental. } \\
\text { Hace inversiones necesarias } \\
\text { en infraestructura, equipos } \\
\text { y mantenimiento de centros } \\
\text { educativos. }\end{array}$ \\
\hline Salud & $\begin{array}{l}\text { Promueve y coordina } \\
\text { campañas nacionales } \\
\text { y programas para } \\
\text { salud básica y sanidad. } \\
\text { Desempeña todas } \\
\text { las demás funciones } \\
\text { establecidas por la } \\
\text { Ley } 10 \text { de } 1990 .\end{array}$ & $\begin{array}{l}\text { Los servicios son presta- } \\
\text { dos a través de hospitales } \\
\text { regionales especializados } \\
\text { y universitarios. Conduce } \\
\text { campañas en coordinación } \\
\text { o gracias al nivel central. } \\
\text { Desempeña todas las de- } \\
\text { más funciones establecidas } \\
\text { en la Ley } 10 \text { de } 1990 .\end{array}$ & $\begin{array}{l}\text { Promueve tratamiento } \\
\text { preventivo y rehabilitación de } \\
\text { pacientes en el primer nivel. } \\
\text { Provee servicios médicos a } \\
\text { través de hospitales locales y } \\
\text { clínicas, y mediante actividades } \\
\text { relacionadas con sanidad } \\
\text { ambiental. }\end{array}$ \\
\hline Vivienda & $\begin{array}{l}\text { Promueve ayuda técnica } \\
\text { a entidades locales. } \\
\text { Deja de asumir programas } \\
\text { de construcción. } \\
\text { Provee subsidios a } \\
\text { programas municipales. }\end{array}$ & & $\begin{array}{l}\text { Define la regulación para el } \\
\text { desarrollo urbano. Promueve } \\
\text { y participa en proyectos de } \\
\text { vivienda social. } \\
\text { Provee subsidios a vivienda a } \\
\text { los más necesitados. }\end{array}$ \\
\hline $\begin{array}{l}\text { Sanida } \\
\text { básica }\end{array}$ & $\begin{array}{l}\text { Conduce programas de } \\
\text { asistencia técnica para } \\
\text { entidades territoriales. } \\
\text { Cofinancia y provee } \\
\text { créditos. }\end{array}$ & & $\begin{array}{l}\text { Provee servicios (directa o } \\
\text { indirectamente, a través de } \\
\text { contratos con el sector privado). } \\
\text { Conduce proyectos para } \\
\text { construcción y expansión de } \\
\text { acueductos y alcantarillados. } \\
\text { Garantiza la prestación de } \\
\text { servicios básicos rurales de } \\
\text { sanidad, limpieza urbana, } \\
\text { saneamiento de mataderos y } \\
\text { plazas de mercado. }\end{array}$ \\
\hline
\end{tabular}

Fuente: cuadro elaborado por el autor con información de Lleras \& Posada (1991). 
La Ley 141 de 1994 reglamenta lo establecido en los artículos 360 y 361 de la Constitución, crea el Fondo Nacional de Regalías (FNR) y la Comisión Nacional de Regalías, desarrolla el derecho del Estado a percibir regalías por la explotación de recursos naturales no renovables y establece las reglas para la liquidación y distribución. Esta ley es un avance de la descentralización del Estado en materia fiscal, ya que los municipios en cuyo territorio se exploten recursos no renovables son directamente partícipes de estos dineros.

A fin de realizar ajustes fiscales a los entes territoriales, dado el creciente gasto operativo de estos, entre otras razones, se promulgan las leyes 549 de 1999, 550 de 1999 y 617 de 2000 , con las cuales, entre varias disposiciones, se clasifican los departamentos y municipios en categorías de acuerdo con su población e ingresos corrientes de libre destinación (ICLD), además, se dispone que los gastos de funcionamiento deben ser cubiertos por los ingresos generados de su ejercicio tributario (ingresos propios).

Como avances en el plano fiscal de la descentralización y como mecanismo para fortalecer el ingreso de los diferentes niveles de Gobierno, se promulgan las leyes 663 de 2000, 788 de 2002, 863 de 2003 y 1111 de 2006, las cuales fortalecen el estatuto tributario y crean nuevos impuestos, como el gravamen a los movimientos financieros (GMF), el cual es de orden nacional.
Para el 2001, la Ley 715 establece las normas que van a regir en materia de distribución y asignación de competencias establecidas por la Constitución Nacional, de acuerdo con sus artículos 151, 288, 356 y 357, y consagra otras disposiciones. Esta ley reforma el sistema de participaciones, crea el Sistema General de Participaciones (SGP), el cual está constituido por los recursos que la nación transfiere por mandato de los artículos 356 y 357 de la Constitución Política de Colombia a los entes territoriales.

Para el año 2007 se vuelve a modificar el SGP con la Ley 1176. Esta variación se realiza en cuanto a los porcentajes dispuestos para los sectores de salud, educación, saneamiento básico y agua potable, propósitos generales y asignaciones especiales. Los porcentajes de distribución de los recursos que entrega el Gobierno central a través del SGP en las diferentes leyes, quedan de la siguiente manera:

Ley 60 de 1993: educación, el30\%; salud, el $25 \%$; agua potable y saneamiento básico, el $20 \%$; deporte, cultura y recreación, $5 \%$, libre destinación, 20 $\%$. Esta última -libre destinación- varía de acuerdo con el porcentaje de la población rural, según lo dispuesto en el artículo 22 de la misma ley.

Ley 715 de 2001: educación, el 58,5 $\%$; salud, $24,5 \%$; propósitos generales, $17 \%$. Del $100 \%$ de los recursos de 
propósitos generales equivalentes al $17 \%$ de los recursos del SGP, se distribuyen en los siguientes sectores así: agua potable y saneamiento básico, el $41 \%$; deporte, cultura y recreación, el $7 \%$; Fonpet, el $10 \%$; libre destinación, el $42 \%$.

Ley 1176 de 2007: educación, 58,5\%; salud, 24,5\%; agua potable y saneamiento básico, 5,4\%; propósitos generales, $11,6 \%$. Del $100 \%$ de los recursos de propósitos generales equivalentes al $11,6 \%$ de los recursos del SGP, se distribuyen en los siguientes sectores de esta forma: deporte cultura y recreación y Fonpet, $83 \%$; libre destinación, $17 \%$.

Finalmente, la Ley 1530 de 2012 modifica los artículos 360, 361 y la ley 141 de 1994, entre otras disposiciones, crea el Sistema General de Regalías (SGR). Esta ley representa en cierto sentido un retroceso en el proceso de descentralización, ya que centraliza los recursos generados vía regalías y hace partícipe de la decisión del gasto de estos recursos al Gobierno central con la creación de los órganos colegiados de administración y decisión (OCAD).

En esta segunda etapa de la descentralización en Colombia el marco legal que la constituye plantea modificaciones que varían aspectos políticos, fiscales y administrativos del proceso de descentralización. En el campo administrativo se presentaron avances con la elección de alcaldes y gobernadores por medio del sufragio popular, con la entrega de nuevas funciones a los gobiernos locales y el aumento de sus competencias; en el plano fiscal, la cesión y participación de rentas del Gobierno central hacia los entes territoriales representan el principal avance en este ámbito. Se puede decir que el proceso de descentralización en Colombia desde sus orígenes y pasando por sus dos etapas, 1983-1990 y 1991 hasta la actualidad, es un proceso que se ha visto fortalecido en materia política, administrativa y fiscal, y que intenta adaptarse a las problemáticas generadas por el mismo proceso.

\section{ANÁLISIS DE LA DESCENTRA- LIZACIÓN FISCAL EN LOS MU- NICIPIOS DEL DEPARTAMENTO DE SANTANDER, DE ACUERDO CON LOS INDICADORES DE DE- PENDENCIA INTERGUBERNA- MENTAL Y ESFUERZO FISCAL, PERIODO 2004-2012}

El análisis que se presentará a continuación se hizo tomando como referencia el promedio de los indicadores de dependencia intergubernamental y esfuerzo fiscal preparados por el Departamento Nacional de Planeación (DNP) durante el periodo comprendido entre 20042012. Para el caso se decidió dividir a los municipios en tres categorías de acuerdo con el desempeño de sus indicadores, con el fin de que las categorías cuenten con un componente descriptivo en el comportamiento de los municipios en relación con los indicadores planteados para el caso. Para el indicador de de- 
pendencia intergubernamental son: sin dependencia, moderada dependencia, totalmente dependiente. En el caso del indicador de esfuerzo fiscal, las categorías son: sobresaliente, bueno, malo (ver Tabla 2). Se decidió preservar la división en las provincias del departamento de Santander con el fin de presentar una mirada más minuciosa sobre las regiones del departamento.-

Tabla 2. Categorías de acuerdo con el indicador

\begin{tabular}{|l|l|l|l|}
\hline \multicolumn{2}{|c|}{ Dependencia intergubernamental } & \multicolumn{2}{c|}{ Esfuerzo fiscal } \\
\hline Si indicador es $\leq 49,9 \%$ & Sin dependencia & Si indicador es $\leq 49,9 \%$ & Sobresaliente \\
\hline $\begin{array}{l}\text { Si indicador es } \geq 50 \% \\
\text { pero } \leq 59,9 \%\end{array}$ & $\begin{array}{l}\text { Moderada } \\
\text { dependencia }\end{array}$ & $\begin{array}{l}\text { Si indicador es } \geq 50 \% \\
\text { pero } \leq 59,9 \%\end{array}$ & Bueno \\
\hline Si indicador es $\geq 60 \%$ & $\begin{array}{l}\text { Totalmente } \\
\text { dependiente }\end{array}$ & Sí Indicador es $\geq 60 \%$ & Malo \\
\hline
\end{tabular}

Fuente: cuadro elaborado por el autor.

\section{Presentación de los indicadores}

\section{Dependencia intergubernamental}

La dependencia intergubernamental muestra el grado en que inciden los distintos niveles de Gobierno en la actuación de las finanzas públicas de las localidades; esta es medida de acuerdo con la relación entre las transferencias y regalías recibidas por el municipio como proporción de sus ingresos totales (ver Tabla 3). El indicador mide la importancia de estos recursos para el financiamiento de los programas del municipio y refleja en qué medida el municipio depende de las transferencias para la financiación de su plan de desarrollo y el correcto cumplimiento de sus funciones y competencias.

\section{Esfuerzo fiscal}

La capacidad de generación de recursos propios por parte de las localidades entra en el esquema de la entrega de facultades del Gobierno central y departamental, por lo tanto este indicador nos indica el camino que los municipios han recorrido para garantizar el desarrollo de sus propias políticas. El indicador esfuerzo fiscal relaciona los ingresos tributarios como porcentaje del total de los ingresos (ver Tabla 3), de esta forma mide de qué manera se financia el municipio y si este hace lo suficiente para generar recursos propios para el financiamiento de sus programas, o si, por el contrario, estos programas dependen de las transferencias de la nación. 
Realidad fiscal de los municipios del departamento de Santander, en el ...

Jorge Enrique Asela Molina

Tabla 3. Indicadores dependencia intergubernamental y esfuerzo fiscal

\begin{tabular}{|c|c|}
\hline Tema & Indicador \\
\hline Dependencia intergubernamental & Transferencias + regalías / ingresos totales \\
\hline Esfuerzo fiscal & Ingresos tributarios / ingresos totales \\
& \\
\hline
\end{tabular}

Fuente: cuadro elaborada por el autor con información del DNP.

\section{Departamento de Santander, división política}

El departamento de Santander está compuesto por seis provincias que albergan 87 municipios. Las provincias son: Comunera, García Rovira, Guanentina, Mares, Soto y Vélez. Estas se componen de la siguiente manera: Comunera, 16 municipios (Chima, Confines, Contratación, El Guacamayo, Galán, Gámbita, Guadalupe, Guápota, Hato, Oiba, Palmar, Palmas de Socorro, Santa Helena del Opón, Simacota, Socorro, Suaita); García Rovira, 12 municipios (Capitanejo, Carcasí, Cerrito, Concepción, Encino, Guaca, Macaravita, Málaga, Molagavita, San Andrés, San José de Miranda, San Miguel); Guanentá, 18 municipios (Aratoca, Barichara, Cabrera, Cepitá, Charalá, Coromoro, Curití, Encino, Jordán, Mogotes, Ocamonte, Onzaga, Páramo, Pinchote, San Gil, San Juaquín, Valle de San José, Villanueva); Mares, 7 municipios (Barrancabermeja, Betulia, El Carmen de Chucurí, Puerto Wilches, Sabana de Torres, San Vicente de Chucurí, Zapatoca); Soto, 15 municipios (Bucaramanga, California, Charta, El Playón, Floridablanca, Girón, Lebrija, Los Santos, Matanza, Piedecuesta,
Rionegro, Santa Bárbara, Suratá, Tona, Vetas); y Vélez, 19 municipios (Aguada, Albania, Barbosa, Bolívar, Chipatá, Cimitarra, El Peñón, Florián, Guavatá, Guepsa, Jesús María, La Belleza, La Paz, Landázuri, Puente Nacional, Puerto Parra, San Benito, Sucre, Vélez).

\section{Análisis consolidado de los municipios del departamento de Santander en el periodo 2004-2012}

Durante el periodo de estudio el comportamiento del promedio general de todos los municipios del departamento de Santander no es bueno en referencia al indicador de dependencia intergubernamental, ya que estos alcanzaron un porcentaje del 74,4 $\%$ de dependencia de las transferencias de la nación. La tendencia del indicador es sólida durante casi todo el periodo, oscilando entre 73,8 \% y 78,1\% (ver Figura 1), siendo el 2011 el año con menos dependencia de los municipios. Esto puede ser explicado por el repunte del indicador de esfuerzo fiscal, el cual durante los últimos tres años del periodo del análisis, muestra un buen comportamiento en comparación con los años anteriores, pasando en 2009 del $11,7 \%$ al 53,1 \% en 2010 (ver Figura 2). 


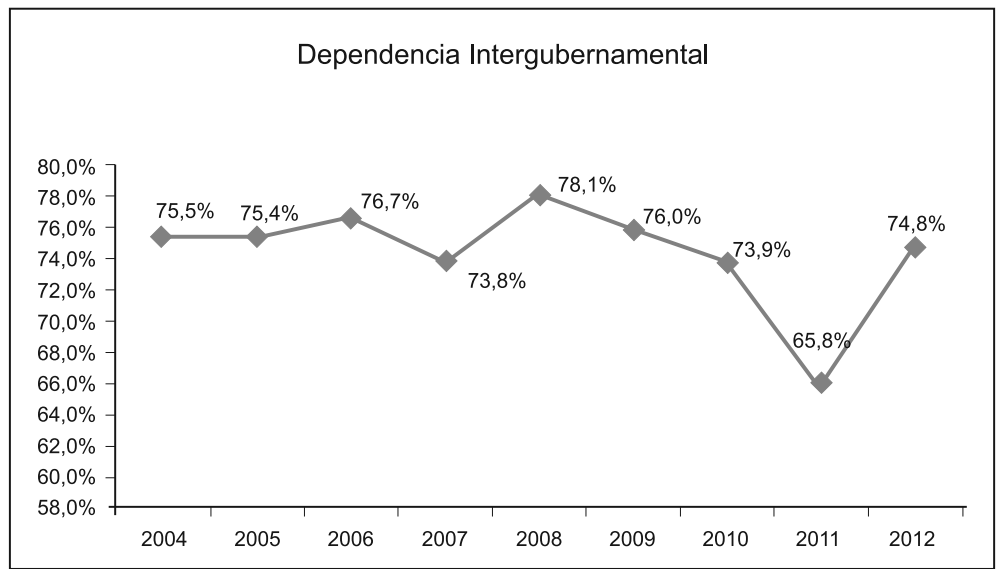

Figura 1. Promédio general de los municipios del departamento de Santander, indicador dependencia intergubernamental (2004-2012).

Fuente: elaborada por el autor con base en datos de DNP.

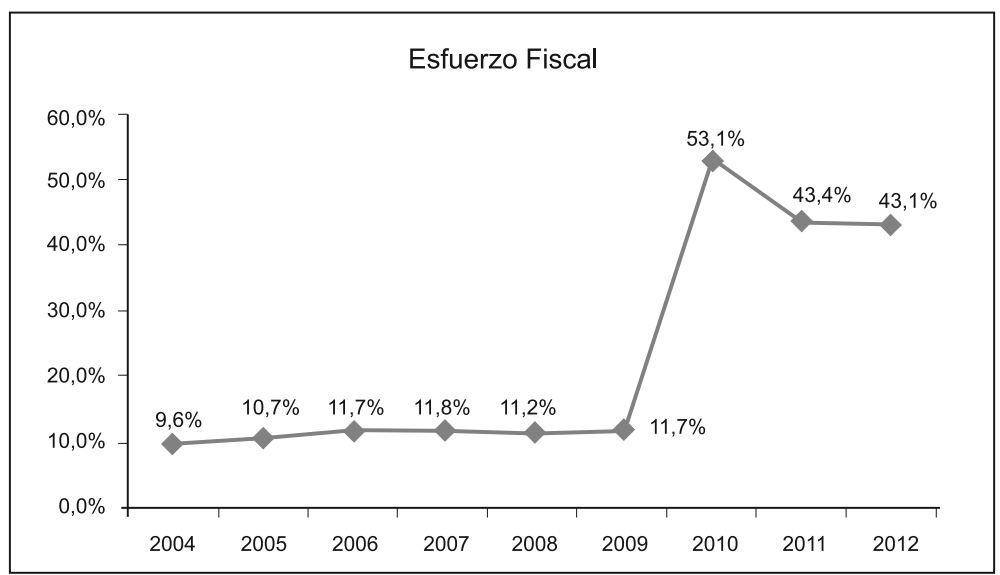

Figura 2. Promedio general de los municipios del departamento de Santander, indicador esfuerzo fiscal (2004-2012).

Fuente: elaborada por el autor con base en datos de DNP.

Dentro del comportamiento del indicador de dependencia integubernamental -como lo veremos más adelante-, de los 87 municipios que componen el departamento de Santander, tan solo 13 no tienen dependencia o esta es moderada (ver mapa 1), (Bucaramanga, Barrancabermeja, Floridablanca, Girón, Piedecuesta, San Gil, Cimitarra, Lebrija, San Vicente de Chucurí, Puerto Wilches, Socorro, Sabana de Torres, Barichara), lo que es preocupante, ya que el $85 \%$ 
de los municipios durante el periodo de y regalías les son entregados para estudio -2004-2012- son dependientes el cumplimiento de sus funciones $\mathrm{y}$ de los recursos que vía transferencias competencias.

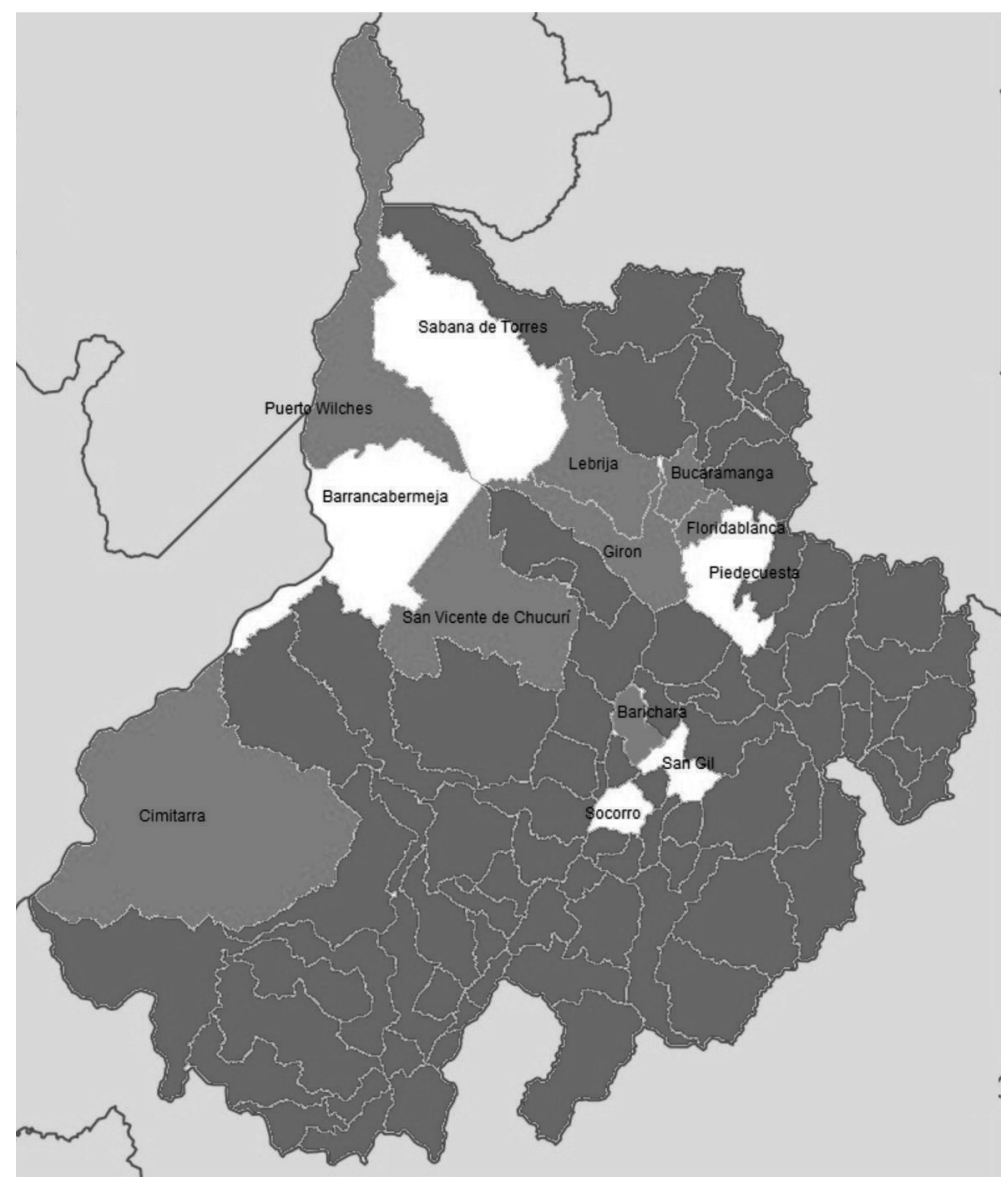

Mapa 1. Municipios del departamento de Santander, de acuerdo con el promedio del indicador de dependencia intergubernamental 2004-2012.

Fuente: mapa elaborado por el autor en base a datos del DNP. Los municipios se dividen en colores de la siguiente manera: Blanco, no tienen dependencia (Barrancabermeja, Piedecuesta, Sabana de Torres, San Gil, Socorro). Azul, moderada dependencia (Barichara, Bucaramanga, Cimitarra, Floridadblanca, Girón, Lebrija, Puerto Wliches, San Vicente de Chucurí). Rojo, totalmente dependiente, 74 municipios restantes). 
Por su parte, el indicador de esfuerzo fiscal presenta un panorama aun más preocupante, ya que tan solo el $5,7 \%$ de los municipios del departamento cuenta con un sobresaliente o buen esfuerzo en la generación de recursos propios (ver mapa 2), (Barrancabermeja, Bucaramanga, Floridablanca, Piedecuesta, San Gil), lo que demuestra que aún hay un camino largo por recorrer en este tema. A su vez, el comportamiento del indicador impide un mejoramineto en la calidad de vida de los habitantes de los municipios del departamento, ya que tan solo el $18 \%$ de los municipios cuenta con un índice de necesidades básicas insatisfechas (NBI) menor al $25 \%$ (ver Tabla 13).

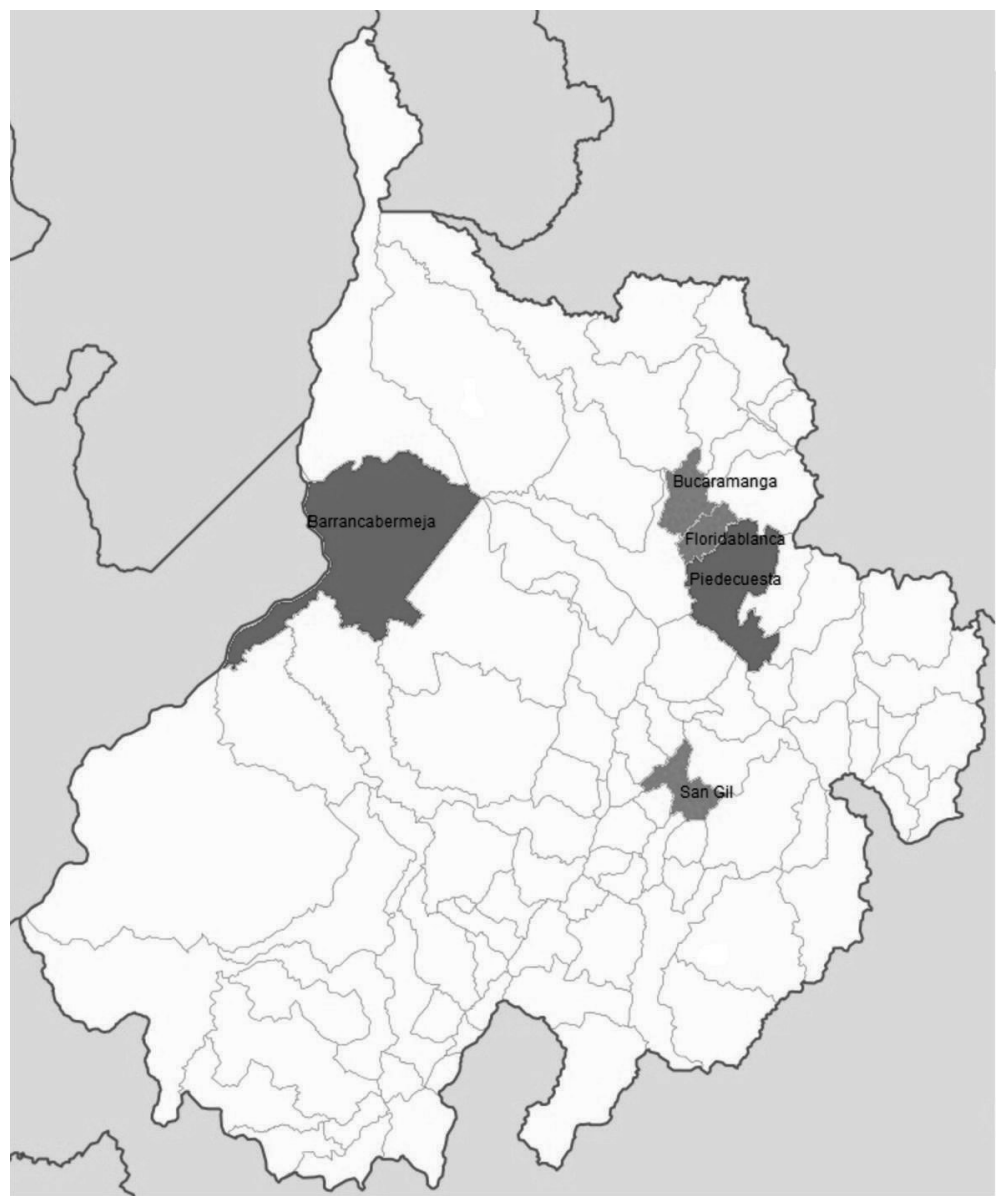

Mapa 2. Municipios del departamento de Santander, de acuerdo con el promedio del indicador de esfuerzo fiscal, 2004-2012.

Fuente: mapa elaborado por el autor en base a datos del DNP. Los municipios se dividen en colores de la siguiente manera: Rojo, municipios con sobresaliente esfuerzo fiscal, (Barrancabermeja, Piedecuesta), Azul, bueno,(Bucaramanga, Floridablanca, San Gil), Blanco, mala,(82 municipios restantes). 
A continuación se presentará el análisis de los indicadores por provincias que, de manera más amplia, mostrará el comportamiento de los municipios del departamento de Santander a la luz de los indicadores de dependencia intergubernamental y esfuerzo fiscal en el periodo comprendido entre 2004-2012.

\section{Análisis por provincias}

\section{Provincia Comunera}

El análisis de los indicadores en la provincia Comunera evidencia una marcada dependencia de los recursos de transferencias y regalías de los diferentes niveles de Gobierno; a su vez, la generación de recursos propios es muy pobre para garantizar el correcto funcionamiento de las administraciones municipales, situación que se puede evidenciar en la Tabla 4.

El indicador de dependencia intergubernamental demuestra que de los 16 municipios que componen la provincia Comunera, tan solo el municipio de Socorro muestra independencia de los recursos de nivel central y departamental para financiar sus políticas, ya que en el promedio de los 9 años los recursos por transferencia y regalías alcanzaron un $44,22 \%$ del total de los ingresos presupuestales.

En lo correspondiente al indicador de esfuerzo fiscal, la provincia Comunera presenta una mala gestión en generación de recursos propios, dado que ninguno de los municipios cuenta con un índice que muestre un esfuerzo superior al 49,99\%, siendo el municipio de Socorro el que más se acerca a esta meta, con un 43,99\% (ver Tabla 4).

\section{Provincia García Rovira}

La provincia de García Rovira es la que cuenta con peor desempeño en el departamento, en cuanto al comportamiento de los indicadores de dependencia intergubernamental y de esfuerzo fiscal, dado que la totalidad de los municipios que la componen son totalmente dependientes de los recursos que vía transferencias y regalías entregan los gobiernos departamental y central (ver Tabla 5), siendo el municipio de Málaga el más cercano a desligarse de dicha dependencia con un porcentaje del 62,06 $\%$ de los ingresos totales provenientes de los entes superiores de Gobierno. 
Tabla 4. Municipios de la provincia Comunera de acuerdo con los indicadores de dependencia intergubernamental y esfuerzo fiscal

\begin{tabular}{|l|c|c|}
\hline \multicolumn{3}{|c|}{ Provincia Comunera } \\
\hline \multicolumn{1}{|c|}{ Municipio } & $\begin{array}{c}\text { Dependencia } \\
\text { intergubernamental }\end{array}$ & Esfuerzo fiscal \\
\hline Chima & $85,68 \%$ & $10,28 \%$ \\
Confines & $76,52 \%$ & $20,99 \%$ \\
Contratación & $81,37 \%$ & $13,67 \%$ \\
El Guacamayo & $81,77 \%$ & $11,8 \%$ \\
Galán & $76,2 \%$ & $13,03 \%$ \\
Gambita & $80,31 \%$ & $18,47 \%$ \\
Guadalupe & $74,42 \%$ & $23,04 \%$ \\
Guapotá & $80,26 \%$ & $23,2 \%$ \\
Hato & $86,44 \%$ & $9,61 \%$ \\
Oiba & $67,42 \%$ & $30,56 \%$ \\
Palmar & $86,35 \%$ & $9,84 \%$ \\
Palmas del Socorro & $76,8 \%$ & $17,72 \%$ \\
Santa Helena del Opón & $88,15 \%$ & $13,74 \%$ \\
Simacota & $79,15 \%$ & $21,09 \%$ \\
Socorro & $44,22 \%$ & $43,99 \%$ \\
Suaita & $69,59 \%$ & $28,91 \%$ \\
\hline
\end{tabular}

Fuente: elaborada por el autor con base $\mathrm{n}$ datos del DNP.

Tabla 5. Municipios de la provincia de García Rovira de acuerdo con los indicadores de dependencia intergubernamental y esfuerzo fiscal

\begin{tabular}{|l|c|c|}
\hline \multicolumn{3}{|c|}{ Provincia García Rovira } \\
\hline \multicolumn{1}{|c|}{ Municipio } & $\begin{array}{c}\text { Dependencia } \\
\text { intergubernamental }\end{array}$ & Esfuerzo fiscal \\
\hline Capitanejo & $78,7 \%$ & $16,96 \%$ \\
Carcasí & $92,03 \%$ & $9,07 \%$ \\
Cerrito & $81,02 \%$ & $15,49 \%$ \\
Concepción & $78,19 \%$ & $15,85 \%$ \\
Enciso & $85,96 \%$ & $11 \%$ \\
Guaca & $88,85 \%$ & $12,68 \%$ \\
Macaravita & $85,24 \%$ & $10,78 \%$ \\
Málaga & $62,06 \%$ & $37,32 \%$ \\
Molagavita & $81,88 \%$ & $10,64 \%$ \\
San Andrés & $73,43 \%$ & $21,52 \%$ \\
San José de Miranda & $85,44 \%$ & $14,2 \%$ \\
San Miguel & $90,77 \%$ & $9,42 \%$ \\
\hline
\end{tabular}

Fuente: elaborada por el autor con base en datos del DNP. 


\section{Provincia Guanentá}

La provincia Guanentá cuenta con 18 municipios, de los cuales Barichara presenta una dependencia moderada en el indicador de dependencia intergubernamental, siendo su indicador del $57,83 \%$, pero en lo correspondiente a esfuerzo fiscal su índice es de $29,02 \%$, lo que evidencia otro tipo de financiación para los programas de su plan de desarrollo. Por otra parte, el municipio de San Gil no tiene dependencia de los recursos de regalías y transferencias para financiar sus políticas públicas, además, el esfuerzo fiscal realizado por el municipio le permite contar con un buen indicador en este rublo, ya que el 57,39 $\%$ de sus ingresos totales provienen de sus ingresos tributarios. El grueso de los municipios de esta provincia muestra un comportamiento totalmente dependiente y malo en la generación de recursos (ver Tabla 6).

Tabla 6. Municipios de la provincia Guanentá de acuerdo con los indicadores de dependencia intergubernamental y esfuerzo fiscal

\begin{tabular}{|l|c|c|}
\hline \multicolumn{3}{|c|}{ Provincia Guanentá } \\
\hline \multicolumn{1}{|c|}{ Municipio } & $\begin{array}{c}\text { Dependencia } \\
\text { intergubernamental }\end{array}$ & Esfuerzo fiscal \\
\hline Aratoca & $76,43 \%$ & $18,81 \%$ \\
Barichara & $57,87 \%$ & $29,02 \%$ \\
Cabrera & $84,38 \%$ & $12,98 \%$ \\
Cepitá & $92,17 \%$ & $9,44 \%$ \\
Charalá & $67,24 \%$ & $28,73 \%$ \\
Coromoro & $83,07 \%$ & $15,58 \%$ \\
Curití & $77,8 \%$ & $21,33 \%$ \\
Encino & $84,35 \%$ & $13,09 \%$ \\
Jordán & $92,47 \%$ & $8,87 \%$ \\
Mogotes & $82,98 \%$ & $18,22 \%$ \\
Ocamonte & $78,06 \%$ & $17,21 \%$ \\
Onzaga & $84,24 \%$ & $12,78 \%$ \\
Páramo & $77,74 \%$ & $25,07 \%$ \\
Pinchote & $71,74 \%$ & $30,75 \%$ \\
San Gil & $36,51 \%$ & $57,39 \%$ \\
San Joaquín & $84,81 \%$ & $9,79 \%$ \\
Valle de San José & $79,3 \%$ & $17,91 \%$ \\
Villanueva & $78,34 \%$ & $18,83 \%$ \\
\hline
\end{tabular}

Fuente: elaborada por el autor con base $\mathrm{n}$ datos del DNP. 


\section{Provincia de Mares}

La provincia de Mares es la que cuenta con mejor desempeño en el indicador de dependencia intergubernamental en el departamento de Santander, dado que el $57 \%$ de los municipios que la componen no tiene dependencia en ese rublo o se sitúa con moderada dependencia (ver Tabla 7), siendo los municipios de Barrancabermeja y Sabana de Torres los de mejor índice de la provincia con un $35,11 \%$-el mejor del departamento- para el primero y $42,08 \%$ para el segundo. Poseen una moderada dependencia de los ingresos de orden central, departamental y de regalías, los municipios de Puerto Wilches con un 52,3\% de sus ingresos totales y San Vicente de Chucurí con $51,3 \%$.

En cuanto al indicador de esfuerzo fiscal, es el municipio de Barrancabermeja el que presenta el mejor índice de la provincia y, a su vez, del departamento: el $66,7 \%$ de sus ingresos totales corresponde a los provenientes de los tributos que vía impuesto recauda el municipio; los demás municipios cuenta con un índice muy bajo, situación que los ubica en una mala posición en cuanto a la generación de recursos propios.

Tabla 7. Municipios de la provincia de Mares de acuerdo con los indicadores de dependencia intergubernamental y esfuerzo fiscal

\begin{tabular}{|l|c|c|}
\hline \multicolumn{3}{|c|}{ Provincia de Mares } \\
\hline \multicolumn{1}{|c|}{ Municipio } & $\begin{array}{c}\text { Dependencia } \\
\text { intergubernamental }\end{array}$ & Esfuerzo fiscal \\
\hline Barrancabermeja & $35,11 \%$ & $66,7 \%$ \\
Betulia & $74,03 \%$ & $30,19 \%$ \\
El Carmen de Chucurí & $72,51 \%$ & $22,03 \%$ \\
Puerto Wilches & $52,3 \%$ & $30,32 \%$ \\
Sabana de Torres & $42,08 \%$ & $36,34 \%$ \\
San Vicente de Chucurí & $51,3 \%$ & $37,18 \%$ \\
Zapatoca & $60,51 \%$ & $25,78 \%$ \\
\hline
\end{tabular}

Fuente: elaborada por el autor con base en datos del DNP. 


\section{Provincia de Soto}

En la provincia de Soto, donde se encuentra situada Bucaramanga, la capital del departamento, el indicador de dependencia intergubernamental tiene un buen comportamiento en los municipios que componen el área metropolitana de Bucaramanga, (Bucaramanga, Floridablanca, Piedecuesta, Girón). El municipio de Piedecuesta cuenta con un índice del 46,31\%, lo cual lo ubica en los municipios que no tienen dependencia de recursos de transferencia y regalías, los municipios de Bucaramanga con 50,02 \%, Floridablanca 52,71 \%, Girón 59,13\% y Lebrija 58,83\%, tienen dependencia moderada de este tipo de recursos; los demás municipios son totalmente dependientes (ver Tabla 8).
En cuanto al indicador de esfuerzo fiscal, nuevamente el municipio de Piedecuesta aparece como el mejor de la provincia con un índice del $60,87 \%$, evidenciando una sobresaliente gestión en la generación de recursos propios. De igual manera, los municipios de Bucaramanga y Floridablanca presentan un buen desempeño en la generación de recursos propios, con índices de 56,58 \% y $52,71 \%$ respectivamente. Cabe resaltar los municipios de Girón 47,86 \% y Lebrija 44,5\% que, si bien no cuentan con un buen desempeño en la generación de recursos propios, sus índices están cerca de llevarlos a dicha posición; los municipios cuentan con un índice muy bajo (ver Tabla 8).

Tabla 8. Municipios de la provincia de Soto de acuerdo con los indicadores de dependencia intergubernamental y esfuerzo fiscal

\begin{tabular}{|l|c|c|}
\hline \multicolumn{3}{|c|}{ Provincia de Soto } \\
\hline \multicolumn{1}{|c|}{ Municipio } & $\begin{array}{c}\text { Dependencia } \\
\text { intergubernamental }\end{array}$ & Esfuerzo fiscal \\
\hline Bucaramanga & $50,02 \%$ & $56,58 \%$ \\
California & $70,48 \%$ & $18,85 \%$ \\
Charta & $87,96 \%$ & $9,61 \%$ \\
El Playón & $84,11 \%$ & $19,69 \%$ \\
Floridablanca & $57,18 \%$ & $52,71 \%$ \\
Girón & $59,13 \%$ & $47,86 \%$ \\
Lebrija & $58,83 \%$ & $44,5 \%$ \\
Los Santos & $69,06 \%$ & $35,56 \%$ \\
Matanza & $84,28 \%$ & $12,86 \%$ \\
Piedecuesta & $46,31 \%$ & $60,87 \%$ \\
Rionegro & $65,22 \%$ & $33,13 \%$ \\
Santa Bárbara & $85,64 \%$ & $10,54 \%$ \\
Suratá & $84,09 \%$ & $10,43 \%$ \\
Tona & $75,99 \%$ & $22,92 \%$ \\
Vetas & $76,46 \%$ & $15,23 \%$ \\
\hline
\end{tabular}

Fuente: elaborada por el autor con base en datos del DNP. 
Provincia de Vélez

La Provincia de Vélez presenta la tendencia de la mayoría de los municipios del departamento en ambos indicadores. En lo correspondiente al indicador de dependencia intergubernamental, el municipio de Cimitarra sobresale frente a los demás, ya que es el único que cuenta con una dependencia moderada en la composición de sus ingresos totales de los dineros que vía transferencias y regalías recibe (su índice es del $50,45 \%$ ). Los demás municipios son totalmente dependientes de los recursos que los diferentes niveles de gobierno les proveen (ver Tabla 9).

En el indicador de esfuerzo fiscal toda la provincia tiene un mal desempeño, dado que los índices en el indicador demuestran un esfuerzo insuficiente por parte de los municipios para generar mayores volúmenes de recursos propios. Hay que resaltar el avance de municipios como Cimitarra y Barbosa, los cuales, dados sus índices 47,62 \% y $43,67 \%$, son los más próximos a tener un buen desempeño en la generación de recursos.

Tabla 9. Municipios de la provincia de Vélez de acuerdo con los indicadores de dependencia intergubernamental y esfuerzo fiscal

\begin{tabular}{|l|c|c|}
\hline \multicolumn{3}{|c|}{ Provincia de Vélez } \\
\hline \multicolumn{1}{|c|}{ Municipio } & $\begin{array}{c}\text { Dependencia } \\
\text { intergubernamental }\end{array}$ & Esfuerzo fiscal \\
\hline Aguada & $85,45 \%$ & $12,82 \%$ \\
Albania & $80,1 \%$ & $11,45 \%$ \\
Barbosa & $67,21 \%$ & $43,67 \%$ \\
Bolívar & $86,27 \%$ & $18,16 \%$ \\
Chipatá & $80,5 \%$ & $15,9 \%$ \\
Cimitarra & $50,45 \%$ & $47,62 \%$ \\
El Peñón & $91,67 \%$ & $8,57 \%$ \\
Florián & $65,62 \%$ & $28,63 \%$ \\
Guavatá & $73,92 \%$ & $19,81 \%$ \\
Guepsa & $74,82 \%$ & $25,2 \%$ \\
Jesús María & $77,47 \%$ & $15,99 \%$ \\
La Belleza & $76,41 \%$ & $25,32 \%$ \\
La Paz & $84,31 \%$ & $14,14 \%$ \\
Landázuri & $74,75 \%$ & $23,26 \%$ \\
Puente Nacional & $64,6 \%$ & $36,03 \%$ \\
Puerto Parra & $59,96 \%$ & $34,4 \%$ \\
San Benito & $84,12 \%$ & $14,63 \%$ \\
Sucre & $88,74 \%$ & $12,09 \%$ \\
Vélez & $69,73 \%$ & $33,08 \%$ \\
\hline
\end{tabular}

Fuente: elaborada por el autor con base $\mathrm{n}$ datos del DNP. 
Después de realizar el análisis de los indicadores por provincias, saltan a la vista algunas particularidades dentro del comportamiento de los indicadores en los municipios, variables como población, extensión geográfica y provincia, que resultan en cierto modo influyentes para el comportamiento de los indicadores en estas localidades.

Como lo vimos anteriormente, el departamento de Santander cuenta con 13 municipios que no tienen o es moderada su dependencia en cuanto a los recursos que vía transferencia y regalías entrega el Gobierno central y departamental. Esto puede ser explicado demográficamente, ya que de los 13 municipios con mayor población del departamento (ver Tabla 10), 11 se encuentran entre los municipios sin o moderada dependencia de este tipo de recursos, siendo Sabana de Torres y Barichara las excepciones. Sumado a esto, de los 5 municipios cuyo indicador de esfuerzo fiscal es sobresaliente o bueno, la totalidad se halla entre los 6 municipios con mayor población dentro del departamento, lo que demuestra una clara relación entre población y generación de recursos.

Tabla 10. Municipios del departamento de Santander con mayor población

\begin{tabular}{|c|c|c|}
\hline Provincia & Municipios & Población \\
\hline Soto & Bucaramanga & 526056 \\
Soto & Floridablanca & 263041 \\
Mares & Barrancabermeja & 191718 \\
Soto & Girón & 166115 \\
Soto & Piedecuesta & 139178 \\
Guanentá & San Gíl & 44937 \\
Vélez & Cimitarra & 41375 \\
Soto & Lebrija & 36138 \\
Mares & San Vicente de Chucurí & 34250 \\
Mares & Puerto Wilches & 31503 \\
Comunera & Socorro & 30142 \\
Vélez & Barbosa & 27877 \\
Soto & Rio negro & 27775 \\
\hline
\end{tabular}

Fuente: elaborada por el autor con base en datos del DANE.

Otra de las particularidades se centra en lo afirmado por Pening (2003), quien plantea que las finanzas públicas de los entes territoriales dependen de su tamaño, es decir, que la generación de recursos propios se encuentra en correlación con el tamaño de la localidad.

En el caso de los municipios del departamento de Santander, podemos 
ver que, en cierto modo, esta condición se cumple, ya que de los 13 municipios que no tienen o su dependencia a los recursos de transferencias y regalías es moderada, 7 se encuentran entre los 15 municipios con mayor extensión territorial, estos son: Cimitarra, Puerto Wilches, Barrancabermeja, Sabana de torres, San Vicente de Chucurí, Girón y Lebrija, (ver Tabla 11), lo cual evidencia cierta relación entre el tamaño del municipio y la dependencia a las transferencias de las localidades. Además, el grueso de los municipios sin o con moderada dependencia se concentran en las provincias de Soto (Bucaramanga, Floridablanca, Girón, Piedecuesta, Lebrija) y de Mares
(Barrancabermeja, San Vicente Chucurí, Puerto Wilches, Sabana de Torres), provincias que presentan los principales cascos urbanos del departamento y los municipios con mayor actividad económica, principalmente en los municipios de la provincia de Soto, que componen el área metropolitana de Bucaramanga y la ciudad de Barrancabermeja. Lo cual demuestra que el principal eje de desarrollo del departamento se sitúa en el norte de este, lo cual puede ser visto a través de los resultados del indicador de esfuerzo fiscal, donde 4 de los 5 municipios son de esta zona del departamento (ver Tabla 12).

Tabla 11. Municipios del departamento de Santander sin o con moderada dependencia intergubernamental de acuerdo con su extensión territorial $\left(\mathrm{km}^{2}\right)$

\begin{tabular}{|l|l|r|r|r|}
\hline \multicolumn{1}{|c|}{ Provincia } & \multicolumn{1}{|c|}{ Municipios } & Población & Área km² & $\begin{array}{c}\text { Posición } \\
\text { según } \\
\text { extensión }\end{array}$ \\
\hline Soto & Bucaramanga & 526056 & 154 & 49 \\
Soto & Floridablanca & 263041 & 101 & 63 \\
Mares & Barrancabermeja & 191718 & 1274 & 3 \\
Soto & Girón & 166115 & 684 & 11 \\
Soto & Piedecuesta & 139178 & 481 & 19 \\
Guanentá & San Gil & 44937 & 150 & 51 \\
Vélez & Cimitarra & 41375 & 2847 & 1 \\
Soto & Lebrija & 36138 & 541 & 15 \\
Mares & San Vicente de Chucurí & 34250 & 1104 & 7 \\
Mares & Puerto Wilches & 31503 & 1588 & 2 \\
Comunera & Socorro & 30142 & 131 & 55 \\
Mares & Sabana de Torres & 19077 & 1153 & 6 \\
Guanentá & Barichara & 7352 & 134 & 54 \\
\hline
\end{tabular}

Fuente: elaborada por el autor con base en datos del DANE. 
Realidad fiscal de los municipios del departamento de Santander, en el ...

Jorge Enrique Asela Molina

Tabla 12. Municipios del departamento de Santander con sobresaliente o buen esfuerzo fiscal

\begin{tabular}{|l|l|r|r|r|}
\hline Provincia & \multicolumn{1}{|c|}{ Municipios } & Población & Área km $\mathbf{~}^{2}$ & $\begin{array}{c}\text { Posición } \\
\text { según } \\
\text { extensión }\end{array}$ \\
\hline Mares & Barrancabermeja & 191718 & 1274 & 3 \\
Soto & Bucaramanga & 526056 & 154 & 49 \\
Soto & Floridablanca & 263041 & 101 & 63 \\
Soto & Piedecuesta & 139178 & 481 & 19 \\
Guanentá & San Gil & 44937 & 150 & 51 \\
\hline
\end{tabular}

Fuente: elaborada por el autor con base en datos del DANE.

Usando la categorización del índice de calidad de vida (NBI) para el año 2012 del DANE (menor a $25 \%$, mayor a $25 \%$ pero menor a $50 \%$ y mayor a $50 \%$ ), encontramos que de los 87 municipios que componen al departamento de Santander, tan solo 16 tienen un índice menor al $25 \%$, representando el $18 \%$ de los municipios del departamento (ver Tabla 13). De estos 16 municipios, la mayoría se centra principalmente en la provincia de Soto -Bucaramanga, Floridablanca, Girón, Piedecuesta, Tona, Vetas- y en el área metropolitana de Bucaramanga, la cual hace parte de la misma provincia. La provincia de Soto es la que cuenta con mejor NBI, ya que para el año 2012 la totalidad de sus municipios se encuentran por debajo del $50 \%$; seguida de cerca por la provincia de Mares, de la cual tan solo el municipio de El Carmen de Chucurí $(51,08 \%$ ) supera el $50 \%$ en el índice. En contraposición al comportamiento de estas dos provincias (Soto, Mares) las restantes provincias (Comunera, García Rovira, Guanentá, Vélez) no presentan un buen NBI, encontrándose la mayoría de los municipios que la componen entre en el $25 \%$ y el 49,9\%. Vale señalar que el $67 \%$ de los municipios del departamento (58) presenta un índice mayor al $25 \%$ pero menor al 50 $\%$, y que solo el $15 \%$, correspondiente a 13 municipios, supera el $50 \%$ (ver Tabla 13).

En relación con la calidad de vida de los municipios del departamento de Santander (NBI) y los indicadores de dependencia intergubernamental y esfuerzo fiscal para el año 2012, se encontró una relación directa entre los municipios que tienen un índice NBI menor al 25 $\%$ y aquellos con mejor indicador de esfuerzo fiscal. De los 16 municipios que cuentan con NBI menor al $25 \%, 11$ presentan sobresaliente o buen esfuerzo fiscal (ver Tabla 14) y 7 de los 11 municipios se encuentran entre los más poblados del departamento (Bucaramanga, Floridablanca, Barrancabermeja, Girón, Piedecuesta, San Gíl, Barbosa).

En lo referente a la relación entre el NBI y el indicador de dependencia intergubernamental para el año 2012, se 
observa que la mitad de los municipios (8) que tienen un NBI menor al $25 \%$, no presenta dependencia (Bucaramanga, Barrancabermeja, San Gil, Socorro) o su dependencia es moderada (Floridablanca, Girón, Málaga, Zapatoca), y los restantes son totalmente dependientes
(Barbosa, Charalá, Guapotá, Ocamonte, Piedecuesta, Pinchote, Tona, Vetas), (ver Tabla 14), lo que evidencia la importancia de los recursos que vía SGP y SGR entrega el Gobierno central a los municipios para la inversión en sectores sociales.

Tabla 13. Distribución número de municipios por provincia de acuerdo con el NBI año 2012

\begin{tabular}{|c|c|c|c|}
\hline Provincia & NBI $<\mathbf{2 5 \%}$ & NBI $>\mathbf{2 5 \%}$ pero $<\mathbf{5 0 \%}$ & NBI $>\mathbf{5 0 \%}$ \\
\hline Comunera & 2 & 12 & 2 \\
García Rovira & 1 & 7 & 4 \\
Guanentina & 4 & 12 & 2 \\
Soto & 6 & 9 & 0 \\
Mares & 2 & 4 & 1 \\
Vélez & 1 & 14 & 4 \\
Total & 16 & 58 & 13 \\
\% & $18 \%$ & $67 \%$ & $15 \%$ \\
\hline
\end{tabular}

Fuente: elaborada por el autor con base en información del DANE y el DNP.

Tabla 14. Municipios con NBI menor al $25 \%$ en relación con indicadores esfuerzo fiscal y dependencia intergubernamental, año 2012.

\begin{tabular}{|l|l|c|l|l|}
\hline Provincia & Municipio & NBI \% & Esfuerzo fiscal & $\begin{array}{c}\text { Dependencia } \\
\text { intergubernamental }\end{array}$ \\
\hline Soto & Bucaramanga & 11,55 & Sobresaliente & Sin dependencia \\
Vélez & Barbosa & 18,80 & Sobresaliente & Totalmente dependiente \\
Mares & Barrancabermeja & 22,33 & Sobresaliente & Sin dependencia \\
Guanentá & Charalá & 24,08 & Bueno & Totalmente dependiente \\
Soto & Floridablanca & 9,43 & Sobresaliente & Moderada dependencia \\
Soto & Girón & 15,37 & Sobresaliente & Moderada dependencia \\
Comunera & Guapotá & 21,67 & Malo & Totalmente dependiente \\
García Rovira & Málaga & 21,24 & Sobresaliente & Moderada dependencia \\
Guanentá & Ocamonte & 24,79 & Malo & Totalmente dependiente \\
Soto & Piedecuesta & 14,36 & Sobresaliente & Totalmente dependiente \\
Guanentá & Pinchote & 22,62 & Sobresaliente & Totalmente dependiente \\
Guanentá & San Gíl & 11,14 & Sobresaliente & Sin dependencia \\
Comunera & Socorro & 15,07 & Malo & Sin dependencia \\
Soto & Tona & 24,10 & Bueno & Totalmente dependiente \\
Soto & Vetas & 20,80 & Malo & Totalmente dependiente \\
Mares & Zapatoca & 18,11 & Malo & Moderada dependencia \\
\hline
\end{tabular}

Fuente: elaborada por el autor con base en información del DANE y el DNP. 
El análisis de los indicadores de dependencia intergubernamental y esfuerzo fiscal en los municipios del departamento de Santander durante el periodo comprendido entre los años 2004-2012, describe una alta dependencia por parte de los entes municipales de los recursos de transferencia, dado que el esfuerzo fiscal no es lo suficientemente fuerte para romper con dicha dependencia. Del mismo modo, el análisis demuestra que los mejores indicadores de los municipios del departamento se encuentran en los municipios del área metropolitana y su zona de influencia (Bucaramanga, Floridablanca, Girón, Piedecuesta, Barrancabermeja), los que presentan las mayores poblaciones (ver Tabla 10) y la mejor calidad de vida (ver Tabla 14).

\section{CONCLUSIONES}

La descentralización, como modelo de estructuración y desarrollo del Estado, evidenció gran progreso en las últimas décadas del siglo XX. Los avances en investigación sobre el concepto han permitido el desarrollo y la consolidación de la descentralización como alternativa de organización de las naciones. Los cambios en el ámbito político, administrativo y fiscal, han posibilitado a los entes subnacionales contar con mayor autonomía en la toma de decisiones sobre las problemáticas que se presenta en sus territorios, mejorando de manera sustancial la eficiencia de la administración pública.

En Colombia el proceso de descentralización se consolidó en la década del 90.
La importancia de esta consolidación radicó en la apertura del poder político hacia los entes territoriales, como también, en la entrega de facultades y responsabilidades para los niveles más bajos de Gobierno. La formulación de un marco normativo que sustentara lo proclamado en la Constitución Política del 91, se convirtió en tarea prioritaria para dar bases sólidas al proceso. La promulgación de leyes como la 60 de 1993, 141 de 1994 y sus posteriores modificaciones (1176 de 2007, 1530 de 2012), son muestra de la adaptabilidad y de los pasos que el proceso de descentralización ha dado en el país.

El análisis del indicador de dependencia intergubernamental para los municipios del departamento de Santander durante el periodo de estudio, evidenció una alta dependencia de estos por los recursos que vía SGP y regalías entrega el Gobierno central, mostrando en el promedio de los años del periodo de estudio un grado de dependencia del $74,4 \%$ de los mencionados ingresos. Del total de municipios del departamento, solo el $15 \%$ no presenta dependencia de estos recursos, o esta es moderada. Del mismo modo, las provincias que tienen mayor dependencia son: Vélez, Guanentá, Comunera y García Rovira; siendo esta última la de peor desempeño, ya que la totalidad de los municipios que la componen presenta dependencia.

El análisis del comportamiento del indicador de esfuerzo fiscal para los municipios del departamento de Santander 
durante el periodo de estudio, mostró un pobre desempeño en la generación de recursos propios, presentando un indicador promedio del $22.9 \%$. Del total de municipios que componen el departamento, solo el 5,7\% presenta un sobresaliente o buen esfuerzo fiscal. La provincia de Soto es la que tiene mejor desempeño, ya que tres de sus municipios se encuentran entre los cinco con sobresaliente o buen esfuerzo fiscal.

Mirando la posible relación entre los indicadores y variables tales como población, extensión geográfica y calidad de vida, se encontró que existe una correlación entre los municipios que no tienen dependencia intergubernamental o esta es moderada, dado que de los 13 municipios en esa condición, 11 se encuentran entre los más poblados. Del mismo modo, dicha correlación también se presenta con el indicador de esfuerzo fiscal, pues de los 5 municipios con sobresaliente o buen esfuerzo fiscal que presenta el departamento, la totalidad se halla entre los 6 municipios más poblados. En cuanto a la extensión geográfica, 7 de los 13 muni- cipios sin o con moderada dependencia se sitúan entre los 15 con mayor extensión geográfica del departamento. Para el indicador de esfuerzo fiscal no se presenta una relación clara entre la extensión geográfica y el esfuerzo fiscal de los municipios. Los resultados entre la relación del indicador de esfuerzo fiscal con el NBI en el año 2012 indicaron que del total de municipios del departamento, 16 presentan un NBI menor al 25\%, 67 mayor al $25 \%$ pero menor al $50 \%$ y 15 mayor al $50 \%$, mostrando el mejor desempeño la provincia de Soto con 6 municipios, de los cuales 4 hacen parte del área metropolitana de Bucaramanga (Bucaramanga, Floridablanca, Girón, Piedecuesta). En lo referente al indicador de dependencia intergubernamental se evidenció que la relación que existe entre los municipios sin o con moderada dependencia no es tan estrecha, ya que si bien la mitad de los municipios con un NBI menor al 25 $\%$ cumplen con dicha condición, la otra mitad es totalmente dependiente, lo que permite ver la importancia de los recursos de transferencias y regalías para la financiación de los sectores sociales.

\section{REFERENCIAS}

Asela, J. (2014). La descentralización en Colombia. ¿Realidad o espejismo? Consideraciones sobre la actualidad del proceso. Revista CEA, 1(1), 65-74.

Baguenard, J. (1994). La décentralisation (4 ed.). Colección: Que sais-je? no. 1879. París: Presse Universitaire de France.

Cohen, J. \& Peterson, S. (1996). Methodological issues in the analysis of decentralization. Cambridge, MA: Harvard Institute for International Development.

Constitución Política de Colombia (2012). Bogotá: Legis. 
Departamento Administrativo Nacional de Estadística. (2010). Estimación y proyección de población nacional, departamental y municipal total por área 1985-2020. Recuperado de: https://www.dane.gov.co/index.php/poblacion-y-demografia/proyecciones-de-poblacion

Departamento Administrativo Nacional de Estadística. (2012). Necesidades básicas insatisfechas $-N B I$, por total, cabecera y resto según municipio y nacional. A junio de 2012. Recuperado de: https://www.dane.gov.co/files/censos/resultados/NBI_total_ municipios_30_Jun_2012.xls

Departamento Nacional de Planeación. (2014). Desempeño Fiscal. Recuperado de https:// www.dnp.gov.co/programas/desarrollo-territorial/evaluacion-y-seguimiento-de-ladescentralizacion/Paginas/desempeno-fiscal.aspx

Falleti, T. (2005). A sequential theory of decentralization: Latin American cases in comparative perspective. American Political Science Review. 99(3), 327-346.

Finot, I. (2002). Descentralización y participación en América Latina: una mirada desde la economía. Revista de la CEPAL, 78, 139-149.

Garay, J. (1994). Descentralización, bonanza petrolera y estabilización. Bogotá: FESCOL.

Iregui, A, Ramos, J. \& Saavedra, L. (2001) Análisis de la descentralización en Colombia. Recuperado de http://www.banrep.gov.co/docum/ftp/borra175.pdf

Lleras, C. \& Posada, J. (1991). Descentralización política, fiscal y administrativa después de la Constitución de 1991. Bogotá: Fundación Presencia.

Mardonez, R. (2008). Descentralización: una definición y una evolución de la agenda legislativa chilena (1990-2008). Revista Eure, 34(102), 39-60.

Pening, J. (2003). Evaluación del proceso de descentralización en Colombia. Economía y Desarrollo, 2(1), 123-149.

Porras, O. (2005, abril). La descentralización en Colombia: estado actual y perspectivas. En Seminario internacional Descentralización: transformación del régimen político y cambio en el modelo de desarrollo, Bogotá, Colombia.

Rondinelli, D., Mccullough, J. \& Johnson, R. (1989). Analyzing decentralization policies in developing countries: political-economy framework. Development and Change, 20(1) 57-87.

Schneider, A. (2003). Decentralization: conceptualization and measurement. Studies in Comparative International Development, 30(3) 32-56.

Treisman, D. (2002). Defining and measuring decentralization: a global perspective. Working paper. California: University of California. 